\title{
Síntese e Propriedades do Amoníaco, numa Actividade PrátICA DE LABORATÓRIO
}

\author{
Mário Valente*(a), Helena Moreira* \\ Neste artigo propõe-se a realização de um trabalho prático simples, integrado no programa de Física e Química A (nível \\ 2), disciplina do $11^{\circ}$ ano ou do $12^{\circ}$ ano. Trata-se da sintese de pequenas quantidades de amoníaco com o fim de estudar \\ algumas das suas propriedades físicas e químicas mais características. É de notar que este trabalho prático pode ser \\ efectuado com meios rudimentares, em qualquer laboratório escolar.
}

\section{INTRODUÇÃO}

O programa da disciplina de Física e Química A (nível 2) para o $11^{\circ}$ ano (ou $12^{\circ}$ ano) [1] de escolaridade está, para o bem e para o mal, quase completamente centrado no amoníaco, usando-o como exemplo de:

- Um processo de síntese industrial (e laboratorial), na introdução aos cálculos estequiométricos (1.1. O amoníaco como matéria prima);

- Perigos associados à manipulação de substâncias químicas e suas consequências ambientais (1.2. O amoníaco, a saúde e o ambiente);

- Energética da formação e quebra de ligações no decurso de reacções químicas (1.3. Síntese do amoníaco e balanço energético);

- Processos de equilíbrio químico e suas características (1.4. Produção industrial do amoníaco);

- O princípio de Le Châtelier aplicado à síntese industrial (1.5. Controlo da produção industrial).

À luz do programa desta disciplina, a preparação de pequenas quantidades desta substância em laboratório é interessante, já que permite em primeira mão, por parte dos alunos, a verificação de algumas das propriedades físicas e químicas do amoníaco. No decurso do trabalho podem explorar-se com a profundidade desejada conceitos teóricos constantes do referido programa como: reacções completas/ /incompletas, processos ácido/base,

Colégio D. Duarte, Rua Visconde de Setúbal, 86 4200-497 Porto

*a)madmage1@yahoo.com cálculos estequiométricos (reagente limitante, reagente em excesso e pureza de uma substância), considerações sobre segurança laboratorial e problemas ambientais entre outros.

\section{Características do amoníaco [2]}

O amoníaco é, nas condições normais de pressão e temperatura, um gás, menos denso que o ar:

$\rho\left(\mathrm{NH}_{3}, 0^{\circ} \mathrm{C}, 1 \mathrm{~atm}\right)=0,77 \mathrm{~g} / \mathrm{dm}^{3}$ contra $\rho\left(\mathrm{ar}, 0^{\circ} \mathrm{C}, 1 \mathrm{~atm}\right)=1,3 \mathrm{~g} / \mathrm{dm}^{3}$. Este gás liquefaz-se a $-33,4^{\circ} \mathrm{C}$ e solidifica a $-77,7^{\circ} \mathrm{C}$.

O amoníaco é detectável pelo olfacto humano a partir dos 20 a 50 ppm, e causa irritação dos olhos e vias respiratórias a partir dos 100 a 200 ppm. Valores superiores a estes são susceptíveis de causar irritações graves. O Volume Limite Tolerado (VLT) de amoníaco em atmosferas de trabalho é de $25 \mathrm{ppm}\left(18 \mathrm{mg} / \mathrm{m}^{3}\right)$.

Misturas de amoníaco com ar contendo entre 16 e $25 \%$ desse gás constituem misturas explosivas, com uma temperatura de ignição de $651^{\circ} \mathrm{C}$.

\section{UtiLizAÇões do AMONÍACo}

Este composto inorgânico de utilização muito importante a nível industrial, no fabrico do ácido nítrico e da ureia, bem como de produtos farmacêuticos, entre muitos outros, é também usado a nível agrícola, sob a forma de adubos azotados, e a nível doméstico, em alguns produtos de limpeza.

Uma das importantes utilizações do amoníaco (liquefeito) é como fluido de transferência de calor, em instalações frigoríficas industriais e domésticas, já que os clorofluorocarbonetos (CFC's), que eram usados para esse fim, foram banidos devido ao seu forte efeito destrutivo para a camada de ozono.

\section{Prática de Laboratório}

A preparação laboratorial do amoníaco pode ser conseguida fazendo reagir qualquer sal de amónio com uma base forte. O procedimento proposto faz uso do sulfato de amónio e do hidróxido de sódio, sais facilmente encontrados no comércio (o primeiro é um adubo agrícola de uso corrente e o segundo é um desentupidor de canos de uso doméstico).

O processo de síntese pode ser descrito pela seguinte equação química: $\left(\mathrm{NH}_{4}\right)_{2} \mathrm{SO}_{4}(\mathrm{aq})+2 \mathrm{NaHO}(\mathrm{aq}) \rightarrow$ $\mathrm{Na}_{2} \mathrm{SO}_{4}(\mathrm{aq})+2 \mathrm{H}_{2} \mathrm{O}(\mathrm{l})+2 \mathrm{NH}_{3}(\mathrm{~g})$

Assim, num tubo de ensaio de tamanho médio $(\varnothing=10 \mathrm{~mm}, \ell=16 \mathrm{~cm})$ colocam-se cerca de $2,0 \mathrm{~g}$ de sulfato de amónio sólido (15 mmol) e 2,0 g de hidróxido de sódio sólido (50 mmol) garantindo assim um meio reaccional fortemente básico. Adiciona-se de seguida cerca de $1 \mathrm{ml}$ de água, o que dá início à reacção. Tapa-se rapidamente o tubo de ensaio contendo a mistura reaccional com o sistema de rolhas apresentado na figura $1 \mathrm{~A}$, apertando-o, e coloca-se em cima um tubo de ensaio vazio, da forma representada na figura 1B, sem apertar (!), por forma a evitar a formação de pressões elevadas no sistema, e a permitir a saída do ar, que vai sendo substituído pelo 
amoníaco. Logo que se detecte a saída de amoníaco pela parte de baixo do tubo de recolha, este pode ser retirado (sempre na posição invertida) e fechado com uma rolha de borracha, sendo rapidamente substituído por outro tubo de ensaio, com o que se reinicia o processo de recolha.

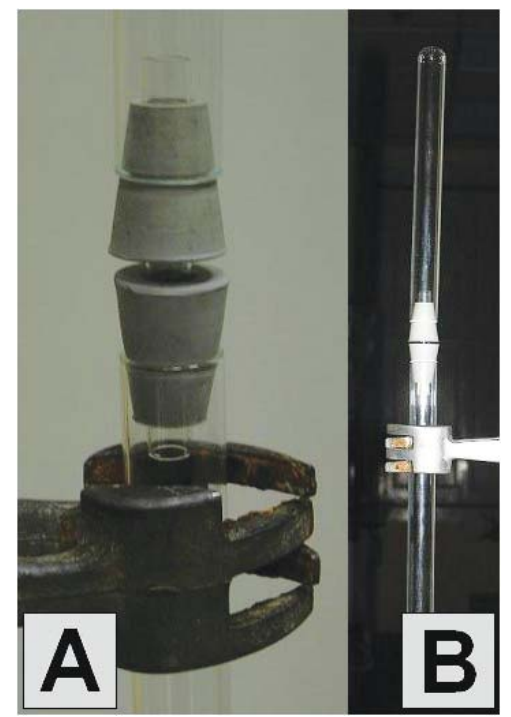

Figura 1 Montagem para a preparação de amoníaco: A - sistema de rolhas usado na montagem e B - montagem completa

Pela estequiometria, ao usar as massas acima referidas é de esperar a formação de cerca de $0,73 \mathrm{dm}^{3}$ de amoníaco, medidos a $20^{\circ} \mathrm{C}$ e $1 \mathrm{~atm}\left(\mathrm{~V}_{\mathrm{M}}\right.$ $\left.=24,1 \mathrm{dm}^{3} / \mathrm{mol}\right)$. Na prática, podem encher-se até quatro tubos de ensaio com este gás, o que é suficiente para as experiências propostas. Veja-se a Nota de Segurança, no fim do artigo.

\section{EXPERIÊNCIA 1:}

\section{A solubilidAdE do AMONíAco EM ÁGUA}

Um dos tubos de ensaio contendo amoníaco é colocado de forma invertida num copo com cerca de $100 \mathrm{ml}$ de água. O nível da água dentro do tubo de ensaio deve subir lentamente até atingir quase o topo, mas subirá mais rapidamente se for agitado.

O volume gasoso que resta no tubo de ensaio é quase exclusivamente ar, já que o amoníaco é extremamente solúvel em água: a $0^{\circ} \mathrm{C}$ dissolvem-se $1148 \mathrm{dm}^{3}$ de $\mathrm{NH}_{3}$ num $\mathrm{dm}^{3}$ de água e a $20^{\circ} \mathrm{C}$ dissolvem-se $738 \mathrm{dm}^{3}$ de $\mathrm{NH}_{3}$ por $\mathrm{dm}^{3}$ de água. Por isso, uma solução aquosa saturada de amoníaco (conhecida como amónia) a $20^{\circ} \mathrm{C}$ contém cerca de $35 \%$ em massa de amoníaco e apresenta uma massa volúmica de cerca de $0,9 \mathrm{~g} / \mathrm{ml}$.

\section{EXPERIÊNCIA 2:}

\section{O CARÁCTER QUÍMICO DA SOLUÇÃo AQUOSA DE AMONÍACO}

Num tubo de ensaio com amoníaco coloca-se rapidamente a água contida numa pipeta Pasteur e, de seguida, três gotas de solução alcoólica de fenolftaleína, que de incolor rapidamente passa a carmim, indicando que a solução aquosa apresenta carácter básico. Esse carácter químico é devido à hidrólise do amoníaco em solução aquosa, segundo:

$$
\begin{aligned}
& \mathrm{NH}_{3}(\mathrm{aq}) \\
& \mathrm{HO}^{-}(\mathrm{aq})
\end{aligned}
$$

que causa o aparecimento de quantidades apreciáveis do ião hidróxido $\left(\mathrm{HO}^{-}\right)$, o que desloca o equilíbrio de autoprotólise da água;

$$
2 \mathrm{H}_{2} \mathrm{O}(\mathrm{I}) \leftrightarrows \mathrm{H}_{3} \mathrm{O}^{+}(\mathrm{aq})+\mathrm{HO}^{-}(\mathrm{aq})
$$

no sentido da diminuição da quantidade de ião hidrónio $\left(\mathrm{H}_{3} \mathrm{O}^{+}\right)$. Como no equilíbrio resultante $\left[\mathrm{HO}^{-}\right] \mathrm{e}>\left[\mathrm{H}_{3} \mathrm{O}^{+}\right] \mathrm{e}, \mathrm{a}$ solução apresenta um carácter básico.

\section{EXPERIÊNCIA 3:}

AcÇÃo do AMONÍAco SOBRE O SULFATO DE COBRE

Num tubo de ensaio com amoníaco coloca-se rapidamente a água contida numa pipeta Pasteur e agita-se, promovendo a dissolução do gás. Adicionam-se então alguns pequenos cristais de sulfato de cobre pentahidratado. A solução adquire uma cor característica, intensamente azul, devido à formação de aminocomplexos de cobre (II), segundo a equação química:

$\mathrm{Cu}^{2+}(\mathrm{aq})+\mathrm{n} \mathrm{NH}_{3}(\mathrm{aq}) \leftrightarrows\left[\mathrm{Cu}\left(\mathrm{NH}_{3}\right)_{\mathrm{n}}\right]^{2+}(\mathrm{aq})$ [eq.4]

\section{EXPERIÊNGIA 4}

\section{A FORMAÇÃO EM FASE GASOSA DO CLORETO DE AMÓNIO}

Uma vareta de vidro cuja ponta foi imersa em ácido clorídrico (cuidado para que a gota não escorra pela vareta, entrando em contacto com a mão - o uso de luvas é aconselhado) é aproximada da boca de um tubo de ensaio com amoníaco. Rapidamente se verifica a formação de uma nuvem branca de cloreto de amónio, segundo a equação química:

$\mathrm{NH}_{3}(\mathrm{~g})+\mathrm{HCl}(\mathrm{g}) \leftrightarrows \mathrm{NH}_{4} \mathrm{Cl}(\mathrm{s}) \quad$ [eq5]

Este processo simula a formação de sulfato e nitrato de amónio em atmosferas poluidas (contendo ácidos sulfúrico e/ou nítrico, resultantes da oxidação atmosférica dos respectivos óxidos). Estes sais, sob a forma de aerossóis, apresentam efeitos prejudiciais a nível do sistema respiratório.

\section{QUESTÕES/DESAFIOS}

É muito importante que se proporcionem questões aos alunos no decurso dos trabalhos práticos. De seguida sugerem-se algumas questões pertinentes que testam o poder de observação e a capacidade de relacionar e operacionalizar conceitos, por parte dos alunos.

- Por que razão se recolheu o amoníaco gasoso num tubo de ensaio invertido?

- Qual o reagente limitante, no processo de síntese usado?

- O que aconteceria à cor da solução resultante da experiência 3, se lhe adicionarmos um ácido? (atente-se às equações 2, 3 e 4).

- Poderá o processo de síntese do amoníaco ser traduzido pela equação 2, considerada no sentido inverso?

- Por que razão é correcto dizer-se que a seta simples usada na equação 1 é apenas justificável pela presença de um grande excesso de hidróxido de sódio?

\section{Conclusão}

Explorar a prática de laboratório nas disciplinas de ciências é fundamental, em particular na situação resultante 
do presente currículo do ensino secundário, do qual foram removidas disciplinas tão fundamentais como as Técnicas Laboratoriais. De facto, a manipulação de equipamento e reagentes de forma minimamente desenvolta é algo que só se consegue com uma prática continuada, e não se pode ter a pretensão de conseguir de forma meramente expositiva.

Consideramos o trabalho proposto como útil, já que proporciona um conhecimento directo de algumas das propriedades físicas e químicas pertinentes apresentadas por uma substância tão frequentemente mencionada no plano teórico, no programa da disciplina.
Nota de Segurança:

Consideremos um laboratório com as dimensões de $5 \times 10 \times 3,5 \mathrm{~m}\left(175 \mathrm{~m}^{3}\right)$ e quatro grupos de alunos a realizar esta experiência, de que resulta um volume total gerado de amoníaco de cerca de $3 \mathrm{dm}^{3}$. Se todo o amoníaco gerado passasse para a atmosfera do laboratório, a sua concentração seria de aproximadamente $3000 \mathrm{~cm}^{3} / 175$ $\mathrm{m}^{3}$, isto é, de cerca de $17 \mathrm{ppm}$, portanto abaixo do VLT de 25 ppm. Naturalmente, apenas uma pequena parcela do amoníaco gerado se escapa para a atmosfera do laboratório pelo que, num laboratório de dimensões normais, não se torna necessário rea- lizar a experiência na hotte. Caso se acumule uma quantidade sensível é aconselhável arejar o laboratório, abrindo algumas janelas durante uns minutos.

\section{REFERÊNCIAS}

[1] Programa da disciplina de Física e Química A (nível 2) $11^{\circ}$ ou $12^{\circ}$ anos: http://www.dgidc.min-edu.pt/programs/ prog_eg.asp

[2] N.N. Greenwood e A.Earnshaw, Chemistry of the Elements, $2^{\mathrm{a}}$ edição, Elsevier, Oxónia, 2005

\section{Actualidades Científicas}

\section{Butanol como Biocombustível}

O produtor de químicos Dupont e a companhia petrolífera BP associaram-se em 2006 numa colaboração com a British Sugar, com o objectivo de estudar a obtenção de butanol a partir de beterraba, para uso como aditivo de gasolina. O potencial desta tecnologia está agora a suscitar uma maior atenção por parte da comunidade científica internacional, havendo outros grupos interessados em contribuir para a introdução do butanol na família dos biocombustíveis. Um exemplo deste interesse crescente é uma equipa de investigação da Washington University de St. Louis (WUSTL) que se encontra a desenvolver novas técnicas de síntese de biocombustíveis baseados no butanol, em alternativa ao seu parente mais leve, o etanol.

As propriedades químicas do butanol são muito semelhantes às do etanol. No entanto, como possui dois carbonos adicionais, assim como os átomos de hidrogénio correspondentes, apresenta um valor energético superior. No que diz respeito ao armazenamento e manuseamento, o butanol é menos corrosivo do que o etanol. Por outro lado, pode ser obtido a partir de biomassa vegetal, incluindo palha, fibras de milho e outros tipos de resíduos agrícolas, que contêm na sua maioria teores elevados de celulose e alguma quantidade de lenhina.

Lars Angenent, professor de Engenharia Química, Ambiental e de Energia na WUSTL, e colaboradores da unidade de investigação de Peoria, IIlinois, do United States Department of Agriculture (USDA) estão a trabalhar com fibras de milho pré-tratadas, um produto secundário do processo de produção de etanol a partir do milho. Uma equipa do USDA, constituída por Bruce Dien e Michael Cotta, desenvolveu e aplicou técnicas físicas e químicas de suavização do material lenho-celulósico, de forma a torná-lo tratável através do processo de digestão. Posteriormente, Angenent e os seus colegas trataram a biomassa lenho-celulósica em digestores, onde o material orgânico foi posto em contacto com uma cultura mista e seleccionada de milhares de microorganismos. Deste modo, a biomassa foi fermentada, obtendo-se ácido butírico como produto do processo. Este ácido carboxílico é um precursor do butanol. O processo de conversão final de ácido butírico a butanol foi realizado também por fermentação, pelo colaborador Nasib Qureshi.
Angenent afirma que "A vantagem deste processo reside na utilização de culturas mistas. Com este tipo de culturas, podemos pegar em qualquer resíduo e convertê-lo num produto com valor, executando apenas algumas manipulações". Deste modo, a alteração do $\mathrm{pH}$ da cultura permite a produção de diferentes produtos. $\mathrm{ApH}$ neutro, é possível obter metano, mas num meio ácido, já se produz ácido butírico, ou mais precisamente iões butirato, que são posteriormente convertidos em butanol. Angenent acrescenta "a biomassa lenho-celulósica é um recurso abundante e renovável, e este processo apresenta-se como uma boa forma de aproveitamento destes resíduos. A sua aplicação permite o desenvolvimento de novas oportunidades económicas para os produtores agrícolas e para as comunidades rurais. Para além disso, este tipo de biomassa é neutra do ponto de vista das emissões de dióxido de carbono". (adaptado de webzine Reactive Reports 72, 2008). 


\section{$\triangle$ Dias de Sousa}

INSTRUMENTAÇÃO ANALÍTICA E CIENTÍFICA, S.A.
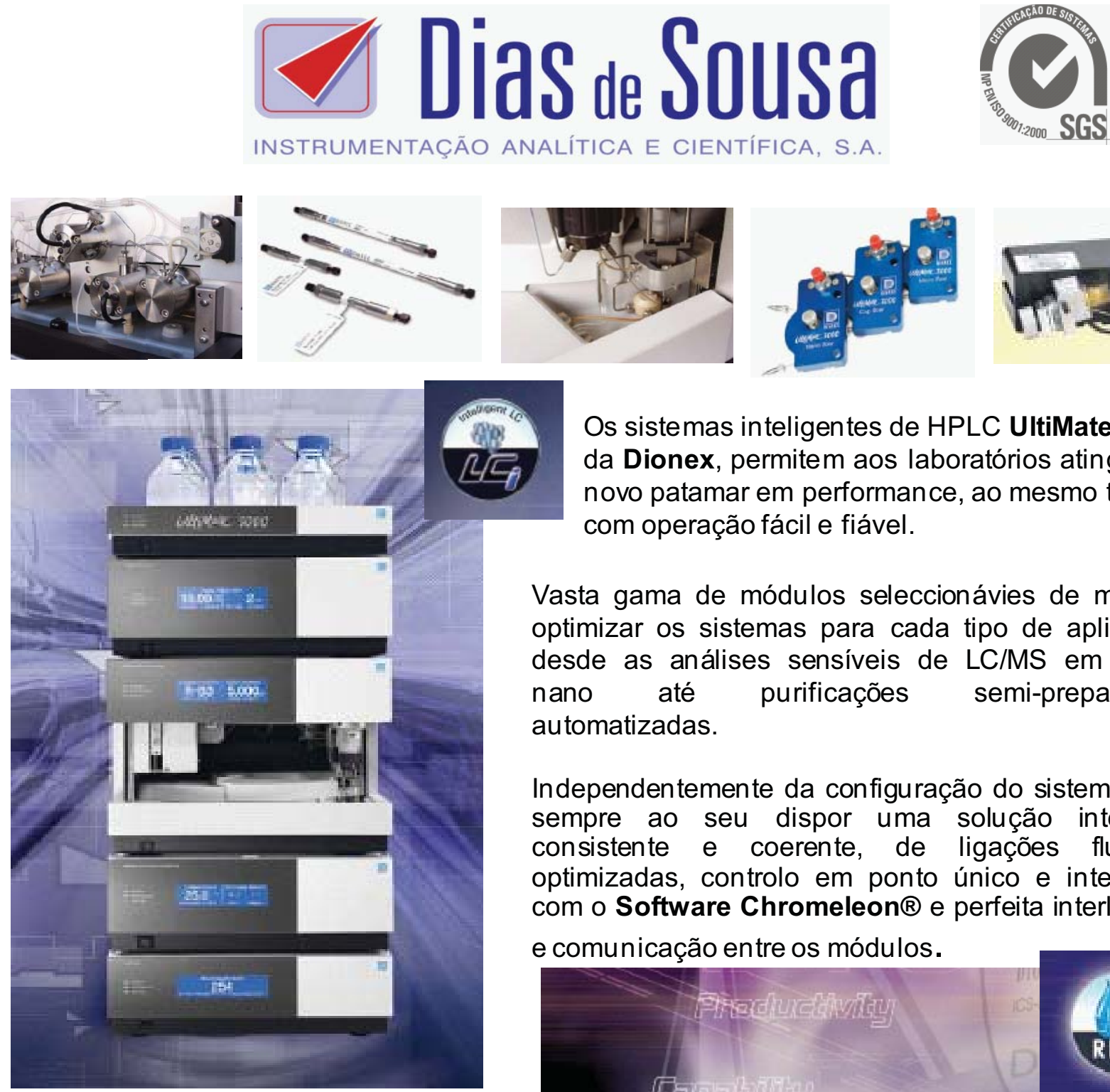

Os sistemas inteligentes de HPLC UltiMate $\mathbf{3 0 0 0}$ da Dionex, permitem aos laboratórios atingir um novo patamar em performance, ao mesmo tempo com operação fácil e fiável.

Vasta gama de módulos seleccionávies de modo a optimizar os sistemas para cada tipo de aplicação, desde as análises sensíveis de LC/MS em fluxos nano até purificações semi-preparativas automatizadas.

Independentemente da configuração do sistema, terá sempre ao seu dispor uma solução integrada consistente e coerente, de ligações fluídicas optimizadas, controlo em ponto único e inteligente com o Software Chromeleon $®$ e perfeita interligação e comunicação entre os módulos.

O Cromatógrafo lónico ICS-3000 Reagent-Free ${ }^{\mathrm{TM}}$ vencedor de vários prémios como melhor produto, permite poupar tempo, trabalho e custos operativos, ao mesmo tempo que aumenta a produtividade e reprodutibilidade das análises iónicas em qualquer aplicação.

Os produtos Dionex são extensivamente usados nas áreas de ambiente, farmácia, biologia, alimentar, biotecnologia, química, petroquímica, energia e electrónica.

As maiores empresas nacionais $e$ mundiais, assim como agências governamentais, Institutos I\&D e Universidades, são clientes Dionex.

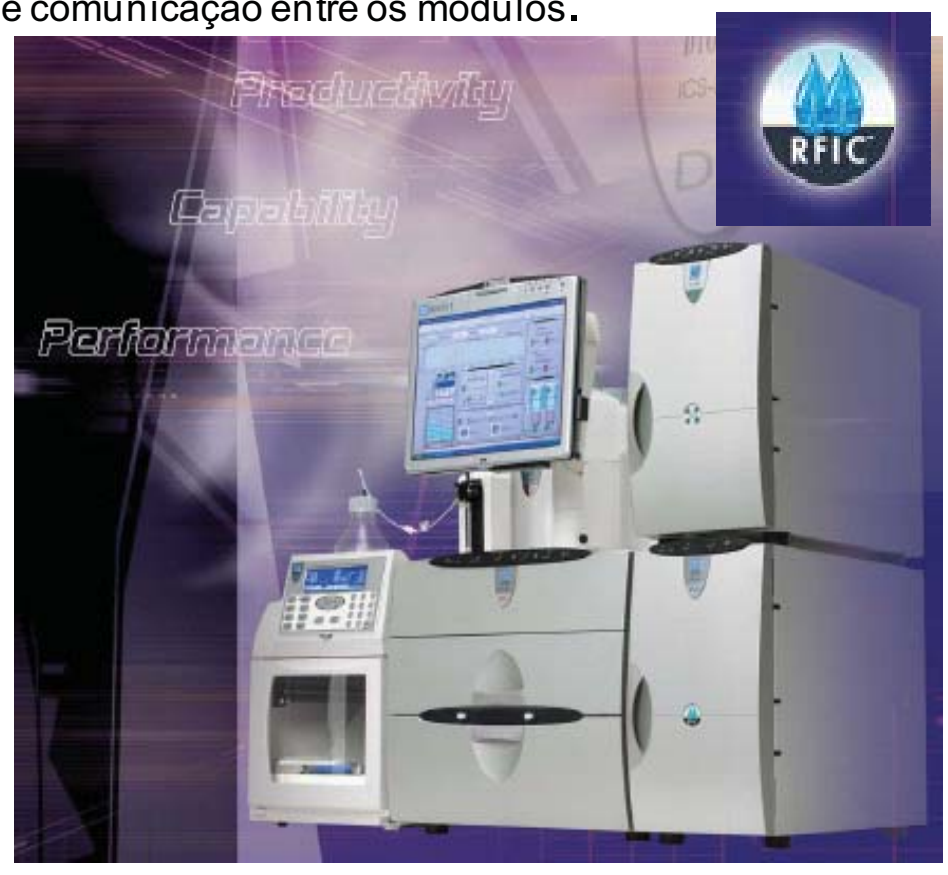

Consulte-nos em

Tel:219533120 Fax:21953 3129 ds@dias-de-sousa.pt www.dias-de-sousa.pt 